\title{
4
}

\section{Hypoxic-Ischemic Brain Injury after Perinatal Asphyxia as a Possible Factor in the Pathology of Alzheimer's Disease}

\author{
Agata Tarkowska
}

Department of Neonate and Infant Pathology, Medical University of Lublin, Lublin, Poland

Author for correspondence: Agata Tarkowska, Department of Neonate and Infant Pathology, Medical University of Lublin, Lublin, Poland. Email: agatatarkowska@umlub.pl

Cite this chapter as: Tarkowska A. Hypoxic-Ischemic Brain Injury after Perinatal Asphyxia as a Possible Factor in the Pathology of Alzheimer's Disease. In: Pluta R, editor. Cerebral Ischemia. Brisbane (AU): Exon Publications; 2021. Online first Aug 31.

Doi: https://doi.org/10.36255/exonpublications.cerebralischemia.2021.perinatalasphyxia

\begin{abstract}
Perinatal asphyxia is a common pathological condition occurring worldwide in approximately 4 million newborns annually. The result of this phenomenon is multi-organ damage and the development of chronic hypoxic encephalopathy. It is currently believed that an episode of cerebral hypoxia/ ischemia may be one of the major factors responsible for the development of Alzheimer's disease-type dementia and/or Alzheimer's disease. It cannot be ruled out that hypoxia in the perinatal period may be a trigger factor for the development of Alzheimer's disease in adulthood. The data from scientific research indicate a possible relationship between hypoxia in the earliest stages of life and the occurrence of long-lasting genetic and biochemical changes leading to the development of neurodegeneration in Alzheimer's disease-type.
\end{abstract}

Keywords: Alzheimer's disease; brain ischemia; genes; hypoxic-ischemic encephalopathy; perinatal asphyxia

In: Cerebral Ischemia. Pluta R (Editor). Exon Publications, Brisbane, Australia. ISBN: 978-0-6450017-9-2; Doi: https://doi.org/10.36255/exonpublications. cerebralischemia.2021

Copyright: The Authors.

License: This open access article is licenced under Creative Commons Attribution-NonCommercial 4.0 International (CC BY-NC 4.0) https://creativecommons.org/licenses/by-nc/4.0/ 


\section{INTRODUCTION}

Perinatal asphyxia (PA) is a condition resulting from insufficient availability of oxygen to various organs and tissues of the fetus and newborn in the antenatal and intranatal periods. The American College of Obstetricians and Gynecologists (ACOG), and the American Academy of Pediatrics (AAP) consider the following criteria for the diagnosis of PA: profound metabolic or mixed acidemia in a newborn with Apgar score of less than 5 at 5 and 10 minutes, with neurological deficits and multiple organ involvement (1). The prevalence of PA is 2 per 1,000 live births in developed countries, but the number of those affected rises to 26 per 1,000 in developing countries (2-7). PA occurs worldwide in approximately 4 million newborns annually (8) and is responsible for $23 \%$ of all infant deaths and $8 \%$ of child deaths (9). As many as $25 \%$ of those who survived have persistent neurological deficits (3), which is the second most frequent cause of neurological disability in the world (4). Despite advances in the treatment of causes, and PA itself, the incidence of perinatal asphyxia has not decreased over the past decade (10). The consequence of PA is the development of hypoxic-ischemic encephalopathy (HIE), diagnosed in 1.8 out of 1,000 live births (11-13), with subsequent deterioration of the postnatal neurological status of newborns.

HIE is the result of a combination of limited oxygen supply to the brain and reduced cerebral blood flow (2-5). The development of nervous tissue at birth is still incomplete, which does not allow for a proper response to pathological conditions. HIE can result in severe neurodevelopmental disorders or death in $24.9 \%$ and $34.1 \%$ of cases, respectively (14). Further observations of infants suffering from PA showed that $27-33 \%$ of those aged 6-7 will present features of intellectual disorders (15). Brain injury occurs secondary to a hypoxic-ischemic episode as well as to reoxygenation-reperfusion following resuscitation (16). HIE in newborns after hypoxia still remains a relatively common and very serious disease entity. It is well known that infants with HIE are at high risk of complications later in life, such as development of neurodegenerative diseases, cognitive impairment, severe mental retardation, learning and behavioral problems, and motor impairments, which develop as long-term consequences $(2,10)$. The high level of unpredictability of the consequences and sequelae of PA makes the treatment strategy and prognosis a real challenge. PA is a globally deepening problem with serious long-term consequences (6). Experts emphasize the need to search for complementary therapies to the currently used hypothermia, as well as to identify and validate biomarkers for both damage and prognosis, in order to develop the best protocol to protect the neonate's brain and reduce disability and death related to this disease (17).

Currently, the main challenge in clinical practice is the unpredictability of this phenomenon and the fact that, once it has started, little can be done to limit its devastating consequences. It is understandable why so much preclinical and clinical research is now focused on searching for early predictors of PA as well as for the determinants of early and late sequelae of asphyxia upon which prophylaxis or effective treatment could be implemented. Moreover, there are many indications that cerebral ischemia and neonatal hypoxia-ischemia may be causally related to Alzheimer's disease (AD) development (18-23). It is currently believed that an episode of cerebral hypoxia may be one of the major factors contributing 
to the development of Alzheimer's-type dementia and/or AD (24-28). Both clinical and experimental studies have shown that after a history of central nervous system ischemia, pathological changes typical of AD can be found, including amyloid deposits and tau protein dysfunction in brain $(26,29-33)$. Studies based on experimental models of brain ischemia have shown secondary dysfunction of genes associated with $\mathrm{AD}$, including those responsible for the production of amyloid, $\beta$-secretase, presenilins or apolipoproteins $(25,33)$. It must be emphasized that AD begins very deceitfully, the moment when the trigger mechanism acts, and when neurodegenerative process begins still remains unknown (34). It cannot be though excluded that hypoxia in perinatal period may result in the development of $\mathrm{AD}$ in adult life. The periods of prenatal and early postnatal life are extremely important for the development of brain structures $(35,36)$. It is often suggested that PA may result in disturbance of the nervous system functions at various stages of life, predisposing to the development of neurodegenerative diseases with age (36). Following a hypoxic-ischemic episode, some neurons die, and others are damaged. This phenomenon occurs in both adults and newborns (37-39). Regardless of the mode of neuronal death, the question remains whether PA provokes the development of delayed complications, including induction of neurodegenerative diseases in adulthood (40).

\section{BRAIN INJURY IN HYPOXIC-ISCHEMIC EPISODE POST-ASPHYXIA}

The risk of brain damage is the greatest in the neonatal period (41). The severity of neurological effects, primarily HIE and its long-term devastating consequences, is directly proportional to the severity of the PA (42). The severity of brain damage is clinically estimated according to the Sarnat method (43): grade 1 (mild), grade 2 (moderate), and grade 3 (severe). It takes into account such parameters as neonatal level of consciousness, neuromuscular functions and autonomic disorders, presence or absence of seizures, and EEG changes. In assessing the severity of complications, this classification also takes into account cardiovascular symptoms such as arrhythmias and disturbances in blood pressure, often observed during the reperfusion period.

Within the central nervous system of full-term newborns, PA causes selective necrosis of the cortical neurons, nuclei of the cranial nerves and the basal ganglia, thalamus, Purkinje cells, anterior horn cells of the spinal cord, as well as the diencephalon, or brainstem. MRI is the gold standard technique to detect patterns of cerebral damage in neonatal HIE (44). Conventional MRI, with T1 and T2 weighted images, have a good diagnostic ability to detect brain damage at the end of the first week following an episode of perinatal hypoxia. Unfortunately, the prognostic value of MRI has significant limitations, and normal images do not guarantee normal neurodevelopment. Changes in MRI in neonates after PA usually involve parasagittal watershed infarcts between anterior/middle cerebral artery and middle/posterior cerebral artery, with both cortical and subcortical involvement, and damage to metabolically active regions, such as the basal ganglia, thalamus, putamen, hippocampus, brainstem, and corticospinal tracts (45). 
Abnormalities of the posterior limb of the internal capsule, basal ganglia, and thalami show the greatest prognostic significance for a poor neurodevelopmental outcome, in particular motor functions (46).

At the cellular level, post-hypoxic brain injury develops in two phases. The first phase takes place during and immediately after asphyxia and has the characteristics of a typical hypoxia. After birth and resuscitation, the condition of the newborn is temporarily stabilized, which lasts for the first few hours of life (6). After about 6 hours, a second pathological phase begins, characterized by hyperemia from previous hypoxia or ischemia, with biochemical changes, such as excitotoxicity, oxidative stress, cytotoxicity and neuroinflammation $(47,48)$. In combination with previous hypoxia and ischemia, it causes a cascade of biochemical reactions leading to the death of cerebral neurons and peri- and postnatal brain atrophy. Apart from the immediate death of neurons (necrosis) during an episode of asphyxia, there is also delayed death of brain neurons (apoptosis) (13). Necrosis develops almost immediately, within minutes. Depletion of the cell's energy reserves and loss of cell membrane integrity result in leakage of cytoplasmic contents and a subsequent neuro-inflammatory response. Conversely, apoptosis is a highly controlled, energy-consuming process that takes time and leads to cellular "suicide" (49). The process of apoptosis significantly contributes to permanent brain damage after asphyxia (16). In the hypoxic brain of the newborn, neuro-inflammatory reaction also develops, characterized by the production of chemokines and cytokines. Inflammatory cells, in particular macrophages and microglia, accumulate at the site of damage and may contribute to further deterioration. In the early period of reperfusion, neutrophils additionally contribute by accumulation in the vascular bed, thus clogging microvessels and disrupting blood circulation (49).

\section{Neuropathology of Alzheimer's disease-type}

Both genetic and environmental factors play a role in the manifestation of $\mathrm{AD}$. AD is characterized by the loss of synapses with subsequent neuronal atrophy through the cerebral cortex, most affecting the medial temporal lobe $(50,51)$. The appearance of $\beta$ amyloid deposits (A $\beta$ ) and neurofibrillary tangles (NFTs) precede clinical symptoms by years, suggesting that the onset of the disease may have occurred many years earlier than the appearance of the first symptoms. A $\beta$ deposits are primarily composed of various 36-43 residues long amyloid peptides that undergo fibrillation to form $A \beta$ plaques resistant to degradation (52). They are often located together with the remnants of neurons, activated microglia, and astrocytes. The amyloid pathology appears to precede the tau protein, with NFTs only found in regions where amyloid was already present. NFTs are intra-neuronal aggregates of the hyperphosphorylated tau protein encoded by the microtubule-associated protein tau gene (53). Although amyloid aggregates and tau protein are associated with neuronal loss and toxicity, they correlate poorly with cognitive decline as $\mathrm{AD}$ progresses. On the other hand, synaptic loss correlates strongly with cognitive loss as a measure of $\mathrm{AD}$ progression (54). The exact mechanism of $\mathrm{AD}$ pathology and neuronal loss remains unclear. The roles of both $A \beta$ and tau protein have been studied extensively over the past few decades, but their role in this disease has yet to be fully explained. Various mechanisms have been proposed to explain what 
actually accounts for the pathogenesis of AD. It is still unclear which changes are primary and which are secondary and what is the first trigger factor. It is very likely that the combination of diverse environmental and genetic factors activates disease through several alternative pathways, ultimately leading to a common mode of neurodegeneration (54).

An episode of cerebral ischemia is proposed as one of the most important risk factors for the development of AD (55-57). Both in humans and animals, cerebral ischemia/hypoxia induces the production and accumulation of $A \beta$ peptide, and additionally impedes the removal of neurotoxic $\beta$ amyloid from the extracellular and intracellular space of the brain $(29,31)$. Additional evidence suggests that ischemic brain injury in humans and animals may contribute to tau protein dysfunction, especially in neurons $(58,59)$. Pre-existing brain damage associated with ischemia/hypoxia and reperfusion may further increase the likelihood of dementia related to $\mathrm{AD}$ development through the proteomic and genomic cascades $(25,60)$. Based on the above observations, it has been suggested that the course of cerebral ischemia in humans and animals is associated with subsequent development of $\mathrm{AD}(24-26,29,57,59,60)$. It should be emphasized that $\mathrm{AD}$ starts very insidiously, and the timing of the first trigger to the development of neurodegeneration is still unknown. Therefore, it cannot be ruled out that hypoxia in the perinatal period may result in the development of AD in adulthood, through mechanisms of perinatal re-programming that affect the expression of individual genes.

\section{Changes of Alzheimer's disease-associated genes and proteins}

The mechanisms of the development of AD after cerebral ischemia and PA are not yet known, but animal models have shown increased expression of genes encoding amyloid protein precursor (APP) and tau protein, the major AD risk factors (18-23). PA in mice causes delayed damage to the hippocampus and a significant deficit in memory and spatial learning (18). Significantly higher concentrations of APP, total tau protein and its phosphorylation, decreased hypoxia-inducible factor, lower levels of amyloid-degrading neprilysin, increased astrocyte-activated amyloid deposition, and brain microglia have been documented (61). Another study demonstrated a significant decrease in $A \beta_{1-42}$ in the cerebrospinal fluid (CSF) of newborns after hypoxia (62). Based on the amyloid hypothesis of AD, reduction of $A \beta_{1-42}$ in CSF is considered the first significant change in this disease (63). In the prodromal and preclinical stage of $A D$, the concentrations of $A \beta_{1-42}$ in CSF are reduced (64), a similar pattern of changes was reported in experimental PA (62). A key point in the cellular response to hypoxia-ischemia is hypoxiainducible factor 1- $\alpha$ (HIF 1- $\alpha$ ). The accumulation of HIF 1- $\alpha$ affects cellular metabolism by increasing anaerobic glycolysis and reducing mitochondrial oxygen consumption. However, in a state of prolonged ischemia, HIF 1- $\alpha$ can cause deleterious effects such as apoptosis and inhibition of cell growth (65). This picture correlates positively with the results of studies showing a tendency to reduce the expression of HIF $1-\alpha$ in lymphocytes of newborns post-asphyxia (66).

The lymphocyte response to $A \beta$, which is a product of $\beta$ - and $\gamma$-secretase action in the brain of AD patients, was first described over 20 years ago (67). The analysis of immunopeptide databases provides evidence that certain proteins 
present in lymphocytes are a source of endogenous neurodegenerative proteins such as APP, presenilin 1 and 2, tau protein, apolipoprotein E, and $\alpha$-synuclein (65). There were no significant differences in the lymphocytic APP and $\beta$-secretase mRNA in vascular dementia, healthy elderly, and AD patients, but their presence in these lymphocytes was confirmed (68). These data correlate positively with a study in which decreased expression of APP and $\beta$-secretase genes was observed in neonates after PA (66). Lymphocytes, primarily associated with inflammation and immune responses, also secrete several pro-neurodegenerative molecules for the initiation and modulation of neurodegeneration (65). It has been shown that 15 days after an episode of PA, overexpression of the $\gamma$-secretase-related presenilin genes occurs in lymphocytes, suggesting that the presenilins may reflect pathological processes in the brain after hypoxia. (66). Increased expression of presenilin genes, related to $\gamma$-secretase metabolizing APP to amyloid, positively correlates with presenilins and amyloid proteins in lymphocytes of patients with neurodegenerative diseases (65).

\section{PERIPHERAL MULTI-ORGAN INJURY IN HYPOXIC-ISCHEMIC BRAIN EPISODE}

Perinatal asphyxia acts primarily on the nervous tissue of the newborn, but also on the heart, lungs, kidneys, and adrenal glands. Initially, the damage is caused by hypoxia, and then related to ischemia and reperfusion (8). Hypoxia leads to redistribution of blood to the brain, heart, lungs, kidneys, and adrenal glands, which originally has a protective effect, but gradually increases the damage to these organs along with the prolonged time of hypoxia (6). All indications are that multi-organ injury, especially cardiovascular failure, plays a key role, especially in the second stage of hypoxic-ischemic encephalopathy and is responsible for high mortality (6). So far, most studies have focused on HIE, but the impact of perinatal hypoxia on other systems and organs also remains very important (6).

Damage to the cardiovascular system in neonates after asphyxia is caused both by hypoxia itself and secondary ischemia, metabolic acidosis, and multiorgan damage (69). Neonatal cardiomyocytes can survive under hypoxic conditions due to the possibility of glycolytic metabolism. However, hypoxia delays the physiological transformation that should occur after birth towards a more efficient, aerobic pathway of energy production. This results in a reduction in ATP production and a less effective contraction. In turn, in the reoxygenation and reperfusion phase, young cardiomyocytes do not yet have fully developed defense mechanisms against the aggression of free oxygen radicals. In the clinical aspect, PA can result in significant disorders of the cardiovascular system-from arrhythmias (including bradycardia), systemic blood pressure disorders (especially hypotension) through dysfunction of the heart muscle with impaired contractility, myocardial ischemia, and persistent pulmonary hypertension of the newborn. All these abnormalities can lead to further impairment of the oxygenation and perfusion of the brain and other organs. So far, no data are available on the longterm consequences of hypoxia on the circulatory system (6). 
Another significant complication is acute kidney injury (AKI), recognized as an almost inevitable consequence of PA, due to the redistribution of blood to the brain, heart, and adrenal glands during an episode of hypoxia, resulting in an additional reduction in renal oxygenation $(70,71)$. In addition, an episode of AKI in the neonatal period has also been associated with an increased risk of developing chronic kidney disease (CKD) later in life (72). The incidence of respiratory dysfunction in infants with PA is 23-86\% (73-75). The spectrum of disorders differs from transient oxygen demand to severe and persistent pulmonary hypertension. The pathogenesis of respiratory system failure is complex, but primary hypoxia is the most important causal factor (2). Intestinal hypoxia and ischemia lead to an increased risk of neonatal necrotizing enterocolitis and gastrointestinal perforation. Liver damage is manifested by hypertransaminasemia and results in plasma coagulation disorders and albumin deficiency (2). In the hematopoietic system, hypoxia leads to increased percentage of nucleated erythrocytes, and thrombocytopenia. Elevated leukocytosis correlates with abnormal neurological outcome (76). The immune system is more prone to systemic infections. Several classification systems for evaluation of the multi-organ damage after PA have been developed. The most well-known, proposed by Shah et al. (73), takes into account renal, cardiac, hepatic and pulmonary parameters. According to the studies conducted by the above authors, renal, cardiovascular, pulmonary, and hepatic disorders occurred in 70\%, 62\%, 86\% and 85\% of hypoxic newborns, respectively.

\section{BIOMARKERS IN POST-HYPOXIC-ISCHEMIC BRAIN INJURY}

The clinical diagnosis of neonatal HIE and the assessment of disease severity are mainly based on the Sarnat Grading Scale, MRI, USG, and EEG. Due to the influence of the progressive disease and other factors, the Sarnat Grading Scale is subjective, and other parameters have limitations and insufficient effectiveness. Therefore, early monitoring of biomarkers associated with neonatal HIE in serum or CSF is particularly important (77). Among the laboratory tests, the acid-base balance takes a special place. The consensus is that lactate levels reflect the degree of hypoxia-ischemia in the fetus, but a single lactate measurement does not provide an answer about the duration of asphyxia. Metabolic acidosis also has some predictive value. Increased metabolic acidosis at birth correlates with severe brain damage in newborns treated with hypothermia (78).

As mentioned earlier, the effects of PA are body-wide, so it is understandable that it can increase the activity of enzymes that are markers of damage to various organs. The relationship between the degree of hypoxia and the activity of transaminases and alkaline phosphatase as well as the concentration of ammonia has been shown (79). Also, early cardiac troponin I levels correlate with the severity of HIE (80). The activation of the immune system is a consistent finding of many studies, as evidenced by the increased levels of cytokines in neonates with HIE. Inflammatory interleukin levels, monocyte chemotactic protein-1 and tumor necrosis factor $\alpha$ are significantly elevated in neonates with HIE and correlate with the severity of HIE and treatment outcome (81). Changes in the concentration of lactate dehydrogenase are associated with lesions in the grey matter of the 
brain and may be an indicator of neurodevelopmental prognosis in infants with HIE (82). Although the abovementioned markers of hypoxia have been studied many times and are quite widely used in clinical practice, there are currently insufficient data to establish cut-off points corresponding to the severity of HIE (83).

Attention was also paid to the possibility of determining the concentration of biomarkers targeting neurovascular system. Calcium-binding proteins and other brain biomarkers were taken into account. Attention was drawn to the increased levels of the S100B protein and neuron-specific enolase (NSE) in the serum of newborns with HIE (84). Moreover, it has been shown that serum levels of S100B and NSE in neonates with HIE were associated with neurodevelopmental disorders at 15 months of age (85). Another study found that serum levels of glial fibrillary acidic protein in the first week of life were elevated in neonates with HIE and were predictors of brain damage present on MRI (86). Another research group showed increased levels of activin A and concluded that this parameter can be taken into account as a prognostic factor (87). Ubiquitin C-terminal hydrolase Ll has a predictive potential for long-term neurological outcomes (88). Scientists are currently focusing on developing new tools for the early estimation of PA severity, in particular for predicting short- and long-term sequelae, in order to reduce mortality, neurological deficits, and multi-organ damage $(4,89)$. Despite investigating various inflammatory mediators, neuronal-specific proteins, microRNAs, metabolite pathways and others, so far, no biomarkers have been conclusively confirmed, especially concerning the long-term sequelae of PA and HIE $(90,91)$. The abovementioned indicators focus mainly on the anatomic-functional features of the hypoxic-ischemic injury, not on dynamic metabolic changes at the cerebral level.

In recent years, scientists have turned towards the use of metabolomics to identify and quantify metabolites present in biological fluids and hypoxic tissues (4). Ultimately, attention should be paid to proteins associated with neurodegenerative diseases such as $\mathrm{AD}$, in particular APP-encoded proteins and presenilins 1 and 2 (65). Metabolomics and genomics, which make it possible to obtain a holistic picture of the metabolic state of the body, seem to provide a powerful platform for assessing the severity and consequences of polymorphic pathological conditions, such as PA. Following this, several studies have recently attempted to assess whether serum tau protein may be a reliable biomarker for the early diagnosis and prognosis of cognitive development after PA. The results of these studies suggest that there is a close relationship between tau protein and perinatal brain injury (92-95). It has also been noticed that the level of tau protein in the serum of newborns with HIE has a prognostic value regarding their long-term neurodevelopmental prognosis (96). According to the available literature, only one study has evaluated the usefulness of $\beta$-amyloid 40 and 42 in serum as a prognostic biomarker in HIE (96). The results of this study seem promising; however, the determinations were carried out only in the first 4 days of life, and no further neurodevelopmental evaluation of patients was conducted.

As the immune system emerges as a potentially important factor in both neurodegenerative diseases and hypoxic brain injury, starting research on lymphocytes seemed logical. It has been proved that in cases of cerebral hypoxia, activated 
lymphocytes can penetrate the central nervous system and participate in the inflammatory process $(65,67,97)$. Based on the conducted research, it turned out that with age, circulating lymphocytes in newborns after PA overexpress presenilin 1 and 2 genes, which are closely related to neurodegenerative diseases, including $\mathrm{AD}$ (66). Moreover, in the same study, it was noticed that the expression of APP, $\beta$-secretase and HIF1- $\alpha$ genes in hypoxic neonatal lymphocytes was lower than in the control group. Increased expression of presenilin genes in lymphocytes may be a promising biomarker for predicting the severity of brain neurodegeneration following neonatal asphyxia and potentially useful for predicting the long-term sequelae of asphyxia later in life.

So far, the knowledge of neonatal HIE and its distant neurological prognosis is incomplete. Early and accurate prognostic methods are needed, both to avoid long-term treatment in those patients who will not respond to it, and, above all, to ensure optimal treatment for patients with a potential for recovery. Research on biomarkers related to post-hypoxic neurodegeneration in neonates is currently at a very early stage of development. The ability to monitor the entire metabolomics and genomics profile and to screen molecular intermediates for different pathological pathways provides a multi-parameter response that appears to be more appropriate in any complex and multi-factorial disease. In addition, studying dynamic changes in genomic profiles can help in various key clinical aspects, including early diagnosis of PA and full-blown HIE, treatment response, and perhaps, prognosis of early and late consequences. The current need is to define a profile or set of biomarkers that can be used in a narrow time window for use in early neuroprotection.

\section{CONCLUSION}

Data suggest that the hallmarks of $\mathrm{AD}$ may also occur during PA, leading to the development of full-blown AD later in life. Thus, PA may contribute to the development of $\mathrm{AD}$, supporting the thesis that environmental factors influence the development of neurodegenerative diseases $(61,98,99)$. Whether this constitutes the etiological basis of neurodegenerative disorders, such as AD in adulthood, still needs to be verified by conducting additional experiments as well as clinical and epidemiological observations (18). Accordingly, since the detailed link between $\mathrm{PA}$ and $\mathrm{AD}$ is very likely, the mechanism by which early life episodes contribute to the development of neurodegenerative disease in adulthood emerges as an exciting new line of research.

Conflict of Interest: The authors declare no potential conflicts of interest with respect to research, authorship, and/or publication of this chapter.

Copyright and Permission Statement: To the best of our knowledge, the materials included in this chapter do not violate copyright laws. All original sources have been appropriately acknowledged and/or referenced. Where relevant, appropriate permissions have been obtained from the original copyright holder(s). 


\section{REFERENCES}

1. Executive summary: Neonatal encephalopathy and neurologic outcome, second edition. Report of the American College of Obstetricians and Gynecologists' Task Force on Neonatal Encephalopathy. Obstet Gynecol. 2014;123:896-901. https://doi.org/10.1097/01.AOG.0000445580.65983.d2

2. Martinello K, Hart AR, Yap S, Mitra S, Robertson N. Management and investigation of neonatal encephalopathy. Arch Dis Child Fetal Neonatal. Ed 2017 update. 2017;02:F346-F358. https://doi. org/10.1136/archdischild-2015-309639

3. Odd D, Heep A, Luyt K, Draycott T. Hypoxic-ischemic brain injury: Planned delivery before intrapartum events. J Neonatal Perinatal Med. 2017;10:347-353. https://doi.org/10.3233/NPM-16152

4. Locci E, Bazzano G, Demontis R, Chighine A, Fanos V, d'Aloja E. Exploring perinatal asphyxia by metabolomics. Metabolites. 2020;10:141. https://doi.org/10.3390/metabol0040141

5. Oorschot DE, Sizemore RJ, Amer AR. Treatment of neonatal hypoxic-ischemic encephalopathy with erythropoietin alone, and erythropoietin combined with hypothermia: History, current status, and future research. Int J Mol Sci. 2020;21:1487. https://doi.org/10.3390/ijms21041487

6. Popescu MR, Panaitescu AM, Pavel B, Zagrean L, Peltecu G, Zagrean AM. Getting an early start in understanding perinatal asphyxia impact on the cardiovascular system. Front Pediatr. 2020;8:68. https://doi.org/10.3389/fped.2020.00068

7. Workineh Y, Semachew A, Ayalew E, Animaw W, Tirfie M, Birhanu M. Prevalence of perinatal asphyxia in East and Central Africa: systematic review and meta-analysis. Heliyon. 2020;6:e03793. https://doi. org/10.1016/j.heliyon.2020.e03793

8. LaRosa DA, Ellery SJ, Walker DW, Dickinson H. Understanding the full spectrum of organ injury following intrapartum asphyxia. Front Pediatr. 2017;5:16. https://doi.org/10.3389/fped.2017.00016

9. Bryce J, Boschi-Pinto C, Shibuya K, Black RE. WHO estimates of the causes of death in children. Lancet. 2005;365:1147-1152. https://doi.org/10.1016/S0140-6736(05)71877-8

10. Albrecht M, Zitta K, Groenendaal F, Van Bel F, Peeters-Scholte C. Neuroprotective strategies following perinatal hypoxia-ischemia: Taking aim at NOS. Free Radic Biol Med. 2019;142:123-131. https://doi. org/10.1016/j.freeradbiomed.2019.02.025

11. Hakobyan M, Dijkman KP, Laroche S, Naulaers, G, Rijken M, Steiner K, et al. Outcome of infants with therapeutic hypothermia after perinatal asphyxia and early-onset sepsis. Neonatology. 2019;115: 127-133. https://doi.org/10.1159/000493358

12. Sugiura-Ogasawara M, Ebara T, Yamada Y, Shoji N, Matsuki T, Kano H, et al. Japan Environment, Children's Study (JECS) Group. Adverse pregnancy and perinatal outcome in patients with recurrent pregnancy loss: Multiple imputation analyses with propensity score adjustment applied to a large-scale birth cohort of the Japan Environment and Children's Study. Am J Reprod Immunol. 2019;81:e13072. https://doi.org/10.1111/aji.13072

13. Smits A, Annaert P, Van Cruchten S, Allegaert K. A physiology-based pharmacokinetic framework to support drug development and dose precision during therapeutic hypothermia in neonates. Front Pharmacol. 2020;11:587. https://doi.org/10.3389/fphar.2020.00587

14. Lutz IC, Allegaert K, de Hoon JN, Marynissen H. Pharmacokinetics during therapeutic hypothermia for neonatal hypoxic ischaemic encephalopathy: a literature review. BMJ Paediatrics Open. 2020;4:e000685. https://doi.org/10.1136/bmjpo-2020-000685

15. Michniewicz B, Szpecht D, Sowińska A, Sibiak R, Szymankiewicz M, Gadzinowski J. Biomarkers in newborns with hypoxic-ischemic encephalopathy treated with therapeutic hypothermia. Childs Nerv Syst. 2020;36:2981-2988. https://doi.org/10.1007/s00381-020-04645-z

16. Solevag AL, Schmolzer GM, Cheung PY. Novel interventions to reduce oxidative-stress related brain injury in neonatal asphyxia. Free Radic Biol Med. 2019;142:113-122. https://doi.org/10.1016/j. freeradbiomed.2019.04.028

17. Higgins RD, Raju T, Edwards AD, Azzopardi VB, Bose CL, Clark RH, et al. National Institute of Child Health and Human Development Hypothermia Workshop Speakers and Moderators. Hypothermia and other treatment options for neonatal encephalopathy: An executive summary of the Eunice Kennedy Shriver NICHD workshop. J Pediatr. 2011;159:851-858. https://doi.org/10.1016/j. jpeds.2011.08.004 
18. Chavez-Valdez R, Lechner C, Emerson P, Northington FJ, Martin LJ. Accumulation of PSA-NCAM marks nascent neurodegeneration in the dorsal hippocampus after neonatal hypoxic-ischemic brain injury in mice. J Cereb Blood Flow Metab. 2020; 41:1039-1057. https://doi.org/10.1177/0271678X20942707

19. Pluta R, Ułamek-Kozioł M, Januszewski S, Czuczwar SJ. Shared genomic and proteomic contribution of amyloid and tau protein characteristic of Alzheimer's disease to brain ischemia. Int J Mol Sci. 2020a;21:3186. https://doi.org/10.3390/ijms21093186

20. Pluta R, Ułamek-Kozioł M, Januszewski S, Czuczwar SJ. Participation of amyloid and tau protein in neuronal death and neurodegeneration after brain ischemia. Int J Mol Sci. 2020b;21:4599. https://doi. org/10.3390/ijms21134599

21. Pluta R, Ułamek-Kozioł M, Kocki J, Bogucki J, Januszewski S, Bogucka-Kocka A, et al. Expression of the tau protein and amyloid protein precursor processing genes in the CA3 area of the hippocampus in the ischemic model of Alzheimer's disease in the rat. Mol Neurobiol. 2020c;57:1281-1290. https:// doi.org/10.1007/s12035-019-01799-z

22. Radenovic L, Nenadic M, Ułamek-Kozioł M, Januszewski S, Czuczwar SJ, Andjus PR, et al. Heterogeneity in brain distribution of activated microglia and astrocytes in a rat ischemic model of Alzheimer's disease after 2 years of survival. Aging (Albany NY) 2020;12:12251-12267. https://doi. org/10.18632/aging.103411

23. Ułamek-Kozioł M, Czuczwar SJ, Januszewski S, Pluta R. Proteomic and genomic changes in tau protein, which are associated with Alzheimer's disease after ischemia-reperfusion brain injury. Int J Mol Sci. 2020;21:892. https://doi.org/10.3390/ijms21030892

24. Snowdon DA, Greiner LH, Mortimer JA, Riley KP, Greiner PA, Markesbery WR. Brain infarction and the clinical expression of Alzheimer disease. The nunstudy. JAMA 1997;277:813-7. https://doi. org/10.1001/jama.1997.03540340047031

25. Pluta R, Furmaga-Jabłonska W, Maciejewski R, Ułamek-Kozioł M, Jabłonski M. Brain ischemia activates $\beta$ - and $\gamma$-secretase cleavage of amyloid precursor protein: significance in sporadic alzheimer's disease. Mol Neurobiol. 2013;47:425-34. https://doi.org/10.1007/s12035-012-8360-z

26. Pluta R, Jabłonski M, Ułamek-Kozioł M, Kocki J, Brzozowska J, Januszewski S, et al. Sporadic Alzheimer's disease begins as episodes of brain ischemia and ischemically dysregulated Alzheimer's disease genes. Mol Neurobiol. 2013;48:500-15. https://doi.org/10.1007/s12035-013-8439-1

27. Pluta R, Ulamek-Koziol M. The role of degenerative pathways in the development of irreversible consequences after brain ischemia. Neural Regen Res. 2019;14:982-983. https://doi.org/10.4103/ 1673-5374.250574

28. Pluta R, Ulamek-Koziol M, Januszewski S, Czuczwar S. From Brain Ischemia to Alzheimer-Like Neurodegeneration. Neuropsychiatry 2018;08(05). https://doi.org/10.4172/Neuropsychiatry. 1000510

29. Pluta R, Kida E, Lossinsky AS, Golabek AA, Mossakowski MJ, Wisniewski HM. Complete cerebral ischemia with short-term survival in rats induced by cardiac arrest. I. Extracellular accumulation of Alzheimer's b-amyloid protein precursor in the brain. Brain Res. 1994;649:323-8. https://doi. org/10.1016/0006-8993(94)91081-2

30. Maslinska D, Laure-Kamionowska M, Taraszewska A, Deregowski K, Maslinski S. Immunodistribution of amyloid beta protein (Ab) and advanced glycation end-product receptors (RAGE) in choroid plexus and ependyma of resuscitated patients. Folia Neuropathol. 2011;49:295-300.

31. Qi J, Wu H, Yang Y, Wand D, Chen Y, Gu Y, et al. Cerebral ischemia and Alzheimer's disease: the expression of amyloid-b and apolipoprotein E in human hippocampus. J Alzheimer's Dis. 2007;12:335-41. https://doi.org/10.3233/JAD-2007-12406

32. Wen Y, Yang SH, Liu R, Perez EJ, Brun-Ziukemagel AM, Koulen P, et al. Cdk5 is involved in NFT-like tauopathy induced by transient cerebral ischemia in female rats. Biochim Biophys Acta 2007;1772:473-83. https://doi.org/10.1016/j.bbadis.2006.10.011

33. Pluta R, Kocki J, Maciejewski R, Ułamek-Kozioł M, Jabłoński M, Bogucka-Kocka A, et al. Ischemia signaling to Alzheimer-related genes. Folia Neuropathol. 2013;50:322-9. https://doi.org/10.5114/ fn.2012.32362

34. Pluta R. Unresolved questions concerning etiology of Alzheimer's disease: hypometabolism. Nutrition. 2011;27:1-2. https://doi.org/10.1016/j.nut.2010.07.010

35. Desplats PA. Perinatal programming of neurodevelopment: epigenetic mechanisms and the prenatal shaping of the brain. Adv Neurobiol. 2015;10:335-361. https://doi.org/10.1007/978-1-4939-1372-5_16 
36. Nalivaeva NN, Turner AJ, Zhuravin IA. Role of Prenatal Hypoxia in Brain Development, Cognitive Functions, and Neurodegeneration. Front Neurosci. 2018;12:825. https://doi.org/10.3389/fnins.2018 .00825

37. Bottiger BW, Schmitz B, Wiessner C, Vogel P, Hossman KA. Neuronal stress response and neuronal cell damage after cardiocirculatory arrest in rats. J Cereb Blood Flow Meta. 1998; 18:1077-1087. https:// doi.org/10.1097/00004647-199810000-00004

38. Laptook AR, Corbett R, Sterett R, Burns DK, Tollefsbol G, Garcia D. Modest hypothermia provides partial neuroprotection for ischemic neonatal brain. Pediatr Res. 1994;35:436-442. https://doi. org/10.1203/00006450-199404000-00010

39. Thompson CB. Apoptosis in the pathogenesis and treatment of disease. Science, 1995;267: 1456-1462. https://doi.org/10.1126/science.7878464

40. Bernert G, Hoeger H, Mosgoeller W, Stolzlechner D, Lubec B. Neurodegeneration, neuronal loss, and neurotransmitter changes in the adult guinea pig with perinatal asphyxia. Pediatr Res. 2003;54: 523-8. https://doi.org/10.1203/01.PDR.0000081760.48331.7A

41. O'Dea M, Sweetman D, Bonifacio SL, El-Dib M, Austin T, Molloy EJ. Management of Multi Organ Dysfunction in Neonatal Encephalopathy. Front Pediatr. 2020;8:239. https://doi.org/10.3389/ fped.2020.00239

42. Le Duc D, Spataru A, Ceanga M, Zagrean L, Schöneberg T, Toescu EC, et al. Developmental exposure to ethanol increases the neuronal vulnerability to oxygen-glucose deprivation in cerebellar granule cell cultures. Brain Res. 2015;1614:1-13. https://doi.org/10.1016/j.brainres.2015.04.009

43. Sarnat HB, Sarnat MS. Neonatal encephalopathy following fetal distress: a clinical and electroencephalographic study. Arch Neurol. 1976; 33:696-705. https://doi.org/10.1001/archneur.1976. 00500100030012

44. Rutherford M, Biarge MM, Allsop J, Counsell S, Cowan F. MRI of perinatal brain injury. Pediatric Radiol. 2010;40:819-33. https://doi.org/10.1007/s00247-010-1620-z

45. Bano S, Chaudhary V, Garga UC. Neonatal hypoxic-ischemic encephalopathy: a radiological review. J Pediatr Neurosci. 2017;12:1-6. https://doi.org/10.4103/1817-1745.205646

46. Shankaran S, McDonald SA, Laptook AR, Hintz SR, Barnes PD, Das A, et al. Neonatal magnetic resonance imaging pattern of brain injury as a biomarker of childhood outcomes following a trial of hypothermia for neonatal hypoxic-ischemic encephalopathy. J Pediatr. 2015;167:987. https://doi. org/10.1016/j.jpeds.2015.08.013

47. Millar LJ, Shi L, Hoerder-Suabedissen A, Molnár Z. Neonatal hypoxia ischaemia: mechanisms, models, and therapeutic challenges. Front Cell Neurosci. 2017;11:78. https://doi.org/10.3389/fncel. 2017.00078

48. Sendeku FW, Azeze GG, Fenta SL. Perinatal asphyxia and its associated factors in Ethiopia: a systematic review and meta-analysis. BMC Pediatr. 2020;20:135. https://doi.org/10.1186/s12887-020-02039-3

49. Antonucci R, Porcella A, Pilloni MD. Perinatal asphyxia in the term newborn. J Pediatr Neonat Individual Med [Internet]. 2014;3:e030269.

50. Kashyap G, Bapat D, Das D, Gowaikar R, Amritkar RE, Rangarajan G, et al. Synapse loss and progress of Alzheimer's disease-A network model. Sci Rep. 2019;9:1-9. https://doi.org/10.1038/ s41598-019-43076-y

51. Chen M-K, Mecca AP, Naganawa M, Finnema SJ, Toyonaga T, Lin S-F, et al. Assessing synaptic density in Alzheimer disease with synaptic vesicle glycoprotein 2A positron emission tomographic imaging. JAMA Neurol. 2018;75:1215-24. https://doi.org/10.1001/jamaneurol.2018.1836

52. Thal DR, Walter J, Saido TC, Fändrich M. Neuropathology and biochemistry of A $\beta$ and its aggregates in Alzheimer's disease. Acta Neuropathol. 2015;129:167-82. https://doi.org/10.1007/s00401 $-014-1375-y$

53. Binder LI, Guillozet-Bongaarts AL, Garcia-Sierra F, Berry RW. Tau, tangles, and Alzheimer's disease. Biochim Biophys Acta-Mol Basis Dis. 2005;1739:216-23. https://doi.org/10.1016/j.bbadis.2004 .08 .014

54. Sheppard O, Coleman M. Alzheimer's Disease: Etiology, Neuropathology and Pathogenesis In: Alzheimer's Disease: Drug Discovery. Huang X (Editor). Exon Publications, Brisbane, Australia. https://doi.org/10.36255/exonpublications.alzheimersdisease.2020 
55. Kim J.H., Lee Y. Dementia and death after stroke in older adults during a 10-year follow-up: Results from a competing risk model. J Nutr Health Aging. 2018;22:297-301. https://doi.org/10.1007/ s12603-017-0914-3

56. Mok VCT, Lam BYK, Wang Z, Liu W, Au L, Leung EYL, et al. Delayed-onset dementia after stroke or transient ischemic attack. Alzheimers Dement. 2016;12:1167-1176. https://doi.org/10.1016/j. jalz.2016.05.007

57. Honig LS, Tang MX, Albert S, Costa R, Luchsinger J, Manly J, Stern Y, Mayeux R. Stroke and the risk of Alzheimer disease. Arch Neurol. 2003;60:1707-1712. https://doi.org/10.1001/archneur.60.12.1707

58. Pluta R, Bogucka-Kocka A, Ułamek-Kozioł M, Bogucki J, Januszewski S, Kocki J, et al. Ischemic tau protein gene induction as an additional key factor driving development of Alzheimer's phenotype changes in CAl area of hippocampus in an ischemic model of Alzheimer's disease. Pharmacol Rep. 2018;70:881-884. https://doi.org/10.1016/j.pharep.2018.03.004

59. Pluta R, Ułamek-Kozioł M, Januszewski S, Czuczwar SJ. Tau protein dysfunction after brain ischemia. J Alzheimers Dis. 2018;66:429-437. https://doi.org/10.3233/JAD-180772

60. Pluta R, Ułamek-Kozioł M. Alzheimer's disease associated genes and their products in brain ischemia: Impact of ischemia on the pathogenesis of Alzheimer's disease. J Ageing Restor. Med. 2018;1:19-27.

61. Zhang X, Li L, Zhang X, Xie W, Li L, Yang D, et al. Prenatal hypoxia may aggravate the cognitive impairment and Alzheimer's disease neuropathology in APPSwe/PS1A246E transgenic mice. Neurobiol Aging 2013, 34, 663-678 https://doi.org/10.1016/j.neurobiolaging.2012.06.012

62. Benterud T, Pankratov L, Solberg R, Bolstad N, Skinningsrud A, Baumbusch L, et al. Perinatal asphyxia may influence the level of beta-amyloid (1-42) in cerebrospinal fluid: An experimental study on newborn pigs. PLoS One 2015;10:e0140966. https://doi.org/10.1371/journal.pone.0140966

63. Karran E, Mercken M, De Strooper B. The amyloid cascade hypothesis for Alzheimer's disease: an appraisal for the development of therapeutics. Nat Rev Drug Discov. 2011;10, 698-712. https://doi. org/10.1038/nrd3505

64. Hansson O, Zetterberg H, Vanmechelen E, Vanderstichele H, Andreasson U, Londos E, et al. Evaluation of plasma Abeta(40) and Abeta(42) as predictors of conversion to Alzheimer's disease in patients with mild cognitive impairment. Neurobiol Aging 2010;31:357-36 https://doi.org/10.1016/j. neurobiolaging.2008.03.027

65. Nataf S, Guillen M, Pays L. Common neurodegeneration-associated proteins are physiologically expressed by human B lymphocytes and are interconnected via the inflammation/autophagyrelated proteins TRAF6 and SQSTM1. Front Immunol. 2019;10:2704. https://doi.org/10.3389/ fimmu.2019.02704

66. Tarkowska A, Furmaga-Jabłońska W, Bogucki J, Kocki J, Pluta R. Alzheimer’s Disease Associated Presenilin 1 and 2 Genes Dysregulation in Neonatal Lymphocytes Following Perinatal Asphyxia. Int J Mol Sci. 2021;22:5140. https://doi.org/10.3390/ijms22105140

67. Gaskin F, Finley J, Fang Q, Xu S, Fu SM. Human antibodies reactive with $\beta$-amyloid protein in Alzheimer's disease. J Exp Med. 1993;177:1181-1186. https://doi.org/10.1084/jem.177.4.1181

68. Herrera-Rivero M, Soto-Cid A, Hernández ME, Aranda-Abreu GE. Tau, APP, NCT and BACEl in lymphocytes through cognitively normal ageing and neuropathology. An Acad Bras Cienc. 2013;85: 1489-149. https://doi.org/10.1590/0001-376520130013

69. Armstrong K, Franklin O, Sweetman D, Molloy EJ. Cardiovascular dysfunction in infants with neonatal encephalopathy. Arch Dis Child. (2012) 97:372-5. https://doi.org/10.1136/adc.2011.214205

70. Behrman R, Lees M, Peterson E, De Lannoy CW, Seeds A. Distribution of the circulation in the normal and asphyxiated fetal primate. Am J Obstet Gynecol. 1970;108:956-69. https://doi.org/ 10.1016/0002-9378(70)90341-8

71. Gouyon JB, Guignard JP. Management of acute renal failure in newborns. Pediatr Nephrol. 2000;14:1037-44. https://doi.org/10.1007/s004670050068

72. Aggarwal A, Kumar P, Chowdhary G, Majumdar S, Narang A. Evaluation of renal functions in asphyxiated newborns. J Trop Pediatr.2005;51:295-9. https://doi.org/10.1093/tropej/fmi017

73. Shah P, Riphagen S, Beyene J, Perlman M. Multiorgan dysfunction in infants with post-asphyxial hypoxic-ischaemic encephalopathy. Arch Dis Child Fetal Neonatal Ed. 2004; 89:F152-5. https://doi. org/10.1136/adc.2002.023093 
74. Hankins GD, Koen S, Gei AF, Lopez SM, Van Hook JW, Anderson GD. Neonatal organ system injury in acute birth asphyxia sufficient to result in neonatal encephalopathy. Obstet Gynecol. 2002; 99: 688-91. https://doi.org/10.1016/S0029-7844(02)01959-2

75. Szakmar E, Jermendy A, El-Dib M. Respiratory management during therapeutic hypothermia for hypoxic-ischemic encephalopathy. J Perinatol. 2019; 39:763-73. https://doi.org/10.1038/ s41372-019-0349-2

76. Sweetman DLP, Molloy E. Poor motor outcome at 2 years of age is predicted by elevated leukocyte count in infants with perinatal asphyxia. Arch Dis Child. 2012;97:A304. https://doi.org/10.1136/ archdischild-2012-302724.1060

77. Lv H, Wang Q, Wu S, Yang L, Ren P, Yang Y, et al. Neonatal hypoxic ischemic encephalopathyrelated biomarkers in serum and cerebrospinal fluid. Clin Chim Acta. 2015;450:282-97. https://doi. org/10.1016/j.cca.2015.08.021

78. Wayock CP, Meserole RL, Saria S, Jennings JM, Huisman TA, Northington FJ, et al. Perinatal risk factors for severe injury in neonates treated with whole-body hypothermia for encephalopathy. Am J Obstet Gynecol. 2014;211:41.el-41.e8. https://doi.org/10.1016/j.ajog.2014.03.033

79. Muniraman H, Gardner D, Skinner J, Paweletz A, Vayalakkad A, Chee YH, et al. Biomarkers of hepatic injury and function in neonatal hypoxic-ischemic encephalopathy and with therapeutic hypothermia. Eur J Pediatr. 2017;176:1295-130. https://doi.org/10.1007/s00431-017-2956-2

80. Montaldo P, Rosso R, Chello G, Giliberti P. Cardiac troponin I concentrations as a marker of neurodevelopmental outcome at 18 months in newborns with perinatal asphyxia. J Perinatol. 2014;34: 292-295. https://doi.org/10.1038/jp.2014.1

81. Chaparro-Huerta V, Flores-Soto ME, Merin Sigala ME, Barrera de León JC, Lemus-Varela ML, TorresMendoza BM, et al. Proinflammatory cytokines, enolase and S-100 as early biochemical indicators of hypoxic-ischemic encephalopathy following perinatal asphyxia in newborns. Pediatr Neonatol. 2017;58:70-76. https://doi.org/10.1016/j.pedneo.2016.05.001

82. Yum SK, Moon CJ, Youn YA, Sung IK. Changes in lactate dehydro-genase are associated with central gray matter lesions in newborns with hypoxic-ischemic encephalopathy. J Matern Fetal Neonatal Med. 2017;30:117 7-1181. https://doi.org/10.1080/14767058.2016.1208745

83. Walas W, Wilińska M, Bekiesińska-Figatowska M, Halaba Z, Śmigiel R. Methods for assessing the severity of perinatal asphyxia and early prognostic tools in neonates with hypoxic-ischemic encephalopathy treated with therapeutic hypothermia. Adv Clin Exp Med. 2020;29:1011-1016. https://doi. org/10.17219/acem/124437

84. Roka A, Kelen D, Halasz J, Beko G, Azzopardi D, Szabo M. Serum S100B and neuron-specific enolase levels in normothermic and hypothermic infants after perinatal asphyxia. Acta Paediatr. 2012;101:319-323. https://doi.org/10.1111/j.1651-2227.2011.02480.x

85. Massaro AN, Chang T, Baumgart S, McCarter R, Nelson KB, Glass P. Bio-markers S100B and neuronspecific enolase predict outcome in hypothermia-treated encephalopathic newborns. Pediatr Crit Care Med. 2014;15: 615-622. https://doi.org/10.1097/PCC.0000000000000155

86. Ennen CS, Huisman TA, Savage WJ, Northington FJ, Jennings JM, Everett AD, et al. Glial fibrillary acidic protein as a biomarker for neonatal hypoxic-ischemic encephalopathy treated with whole-body cooling. Am J Obstet Gynecol. 2011;205:251.el-e. https://doi.org/10.1016/j.ajog.2011.06.025

87. Florio P, Frigiola A, Battista R, Abdalla Ael H, Gazzolo D, Galleri L, et al. Activin A in asphyxiated full-term newborns with hypoxic-ischemic encephalopathy. Front Biosci (Elite Ed). 2010;2:36-42. https://doi.org/10.2741/e62

88. Douglas-Escobar MV, Heaton SC, Bennett J, Young LJ, Glushakova O, Xu X, et al. UCH-Ll and GFAP serum levels in neonates with hypoxic-ischemic encephalopathy: A single center pilot study. Front Neurol. 2014;5:273. https://doi.org/10.3389/fneur.2014.00273

89. Liu, W.; Yang, Q.; Wei, H.; Dong, W.; Fan, Y.; Hua, Z. Prognostic value of clinical tests in neonates with hypoxic-ischemic encephalopathy treated with therapeutic hypothermia: A systematic review and meta-analysis. Front Neurol. 2020;11:133. https://doi.org/10.3389/fneur.2020.00133

90. Graham EM, Everett AD, Delpech JC, Northington FJ. Blood biomarkers for evaluation of perinatal encephalopathy-State of the art. Curr Opin Pediatr. 2018;30:199-203. https://doi.org/10.1097/ MOP.0000000000000591 
91. Murray DM. Biomarkers in neonatal hypoxic-ischemic encephalopathy-Review of the literature to date and future directions for research. Handb Clin Neurol. 2019;162:281-293. https://doi.org/10.1016/ B978-0-444-64029-1.00013-8

92. Ni P, Qiao Y, Tong W, Zhao C, Zheng P. Associations between serum tau, neurological outcome, and cognition following traumatic brain injury. Neurol India. 2020;68:462-467. https://doi.org/ $10.4103 / 0028-3886.284380$

93. Toorell H, Zetterberg H, Blennow K, Sävman K, Hagberg H. Increase of neuronal injury markers Tau and neurofilament light proteins in umbilical blood after intrapartum asphyxia. J Matern Fetal Neonatal Med. 2020;31:2468-2472. https://doi.org/10.1080/14767058.2017.1344964

94. Massaro AN, Wu YW, Bammler TK, Comstock B, Mathur A, McKinstry RC, et al. Plasma Biomarkers of Brain Injury in Neonatal Hypoxic-Ischemic Encephalopathy. J Pediatr. 2018;194:67-75. https:// doi.org/10.1016/j.jpeds.2017.10.060

95. Wu H, Wu H, Li Z, Yang X, Liu J, Wang W, Liu G. SBDPs and Tau proteins for diagnosis and hypothermia therapy in neonatal hypoxic ischemic encephalopathy. Exp Ther Med. 2017;13:225-229. https:// doi.org/10.3892/etm.2016.3911

96. Benavente-Fernandez I, Ramos-Rodriguez JJ, Infante-Garcia C, Jimenez-Gomez G, Lechuga-Sancho A, Lubian-Lopez S, et al. Altered plasma-type gelsolin and amyloid- $\beta$ in neonates with hypoxicischaemic encephalopathy under therapeutic hypothermia. J Cereb Blood Flow Metab. 2019;39: 1349-1354. https://doi.org/10.1177/0271678X18757419

97. Miró-Mur F, Urra X, Ruiz-Jaén F, Pedragosa J, Chamorro Á, Planas AM. Antigen-dependent T cell response to neural peptides after human ischemic stroke. Front. Cell Neurosci. 2020;14:206. https:// doi.org/10.3389/fncel.2020.00206

98. Schiefecker AJ, Putzer G, Braun P, Martini J, Strapazzon G, Antunes AP, et al. Total tau-protein as investigated by cerebral microdialysis increases in hypothermic cardiac arrest: A pig study. Ther Hypothermia Temp Manag. 2021;11:28-34. https://doi.org/10.1089/ther.2020.0016

99. Takahashi K, Hasegawa S, Maeba S, Fukunaga S, Motoyama M, Hamano H, et al. Serum tau protein level serves as a predictive factor for neurological prognosis in neonatal asphyxia. Brain Dev. 2014;36:670-5. https://doi.org/10.1016/j.braindev.2013.10.007 
